\title{
Long-Term Effects of Mind-Body Exercises on the Physical Fitness and Quality of Life of Individuals With Substance Use Disorder-A Randomized Trial
}

OPEN ACCESS

Edited by:

Fabrizio Schifano

University of Hertfordshire,

United Kingdom

Reviewed by:

Christina Athanasopoulou University of West Attica, Greece

Laura Orsolini,

University of Hertfordshire,

United Kingdom

*Correspondence:

Dong Zhu

zhudong@sus.edu.cn

Specialty section:

This article was submitted to

Addictive Disorders,

a section of the journal

Frontiers in Psychiatry

Received: 20 January 2020 Accepted: 30 November 2020 Published: 18 December 2020

Citation:

Zhu $D$, Jiang $M, X u D$ and Schöllhorn WI (2020) Long-Term Effects of Mind-Body Exercises on the Physical Fitness and Quality of Life of Individuals With Substance Use Disorder-A Randomized Trial.

Front. Psychiatry 11:528373. doi: 10.3389/fpsyt.2020.528373

\author{
Dong Zhu ${ }^{1 *}$, Mei Jiang ${ }^{1}$, Ding $X u^{2}$ and Wolfgang I. Schöllhorn ${ }^{1,3}$ \\ 'School of International Education, Shanghai University of Sport, Shanghai, China, ${ }^{2}$ Shanghai Drug Administration, \\ Shanghai, China, ${ }^{3}$ Institute for Sport Science, Johannes Gutenberg-University Mainz, Mainz, Germany
}

Background: Mind-body exercises (MBE) are sequences of low to medium-intensity activities that benefit healthy performers physically and mentally. In contrast to the unmodified application of traditional tai chi, qi gong, or yoga in the healthy population, MBEs are typically tailored for individuals with substance abuse disorder (SUD). Despite numerous applications in practice, the detailed effects of tailor-made MBEs for SUD are unclear.

Objectives: This study aimed to analyze and compare changes in the physical fitness and quality of life of individuals with SUD that underwent conventional or tailor-made MBEs.

Methods: A total of 100 subjects obtained from the Shanghai Mandatory Detoxification and Rehabilitation Center with SUD were randomly assigned into two groups. The subjects in the experimental group $(n=50)$ practiced tailored MBE for 60 min a day, five times a week, for 3 months. The subjects $(n=50)$ in the control group were treated with conventional rehabilitation exercises with the same intervention protocol. The outcomes of fitness and quality of life for drug addiction were measured at the beginning and after 3 and 6 months by a questionnaire (QOL-DA). A two-way repeated measure analysis of variance was applied to compare the difference of treatments in the two groups.

Results: Statistically significant differences for the experimental group were found in systolic $\left(p<0.01, \eta^{2}=0.124\right)$ and diastolic blood pressure $\left(p<0.01, \eta^{2}=0.097\right)$, pulse $\left(p<0.01, \eta^{2}=0.086\right)$, vital capacity $\left(p<0.05, \eta^{2}=0.036\right)$, flexibility $(p<0.01$, $\left.\eta^{2}=0.143\right)$, and aerobic endurance $\left(p<0.01, \eta^{2}=0.165\right)$. Results of the QOL-DA showed statistically significant differences between the experimental and control groups in total score $\left(p<0.01, \eta^{2}=0.158\right)$ with greater effects on the former.

Conclusions: This study provided evidence that tailored MBE could lead to remarkable effects with regard to blood pressure, vital capacity, flexibility, and aerobic endurance in comparison with conventional rehabilitation methods.

Clinical Trial Registration: ChiCTR-IPR-14005343.

Keywords: mind-body exercise, methamphetamine, heroin, tai chi, qi gong, yoga, rehabilitation, quality of life 


\section{INTRODUCTION}

According to the 2019 World Drug Report, released by the United Nations Office on Drugs and Crime in June 2019, a total of 271 million people worldwide used illicit drugs in the previous year, whereby 35 million people were estimated to be suffering from substance use disorder (SUD). For people with SUD, the availability of and access to treatment services remain limited on the global level, as only one in seven people with SUD receives treatment each year (1). In China, 2.4 million drug users were registered nationwide, including 889,000 opioid abusers and 1,350,000 methamphetamine (MA) abusers, accounting for 42.1 and $57.3 \%$, respectively, by the end of 2018 (2). SUD and related psychopathology are persistent problems in public health, which adversely affect the health and social functioning of sufferers, and are a major burden to their families and wider society (1-3). MA use is associated with an increased severity of cardiomyopathy, mental disorder, and damage to the brain caused by neurotoxicity (4-6). Chronic MA addicts exhibit impairment of cognitive functions and poor psychological wellbeing. Therefore, cognitive function must be considered as an important component in the treatment of MA dependence (7). The high relapse rate has been affecting the sustainability of antidrug work worldwide. According to studies in China, the relapse rate for heroin abusers within the first year was $96.68 \%$ (8). To date, non-effective treatment methods are only available amongst amphetamine users (9).

Physical exercise (PE) within a conventional rehabilitation program is widely regarded as a form of "medicine" for the prevention and treatment of myriad somatic health conditions (10). Considerable evidence shows that sports can play a positive role in reducing illicit drug use (11). SUD is currently considered as a brain disease, and PE must be considered as an alternative treatment approach that can induce neuroplasticity on individuals with SUD (12). PE increases the concentration of neurotransmitters, which contribute to exercise-induced reward. In addition, a meta-analysis shows that $\mathrm{PE}$ increases the release of brain-derived neurotrophic factors compared with control conditions (13). PE also evokes hippocampal neurogenesis (14), a process that may positively affect stress-related disorders (10).

\section{Mind-Body Exercise (MBE) as a Potential Therapy for Chronic Diseases}

$\mathrm{MBE}$ is often implemented in patients because of its low physically and emotionally expected risk, relatively low costs, and potential to allow patients to take a more active role in treatment (15). According to the US National Institutes of Health, National Center for Complementary and Integrative Health, mind-body practices focus on the interactions amongst the brain, mind, body, and behavior, with the intent to use the mind to affect physical functioning and promote health (16). Several mind-body therapies have been reported to decrease indicators of sympathetic activation (17-19). Mind-body approaches may satisfy unmet medical needs by relieving symptoms associated with chronic diseases in the management of mild-moderate mental and physical symptoms (15). MBE, such as yoga, tai chi or qi gong are known to have a sustaining influence on the behavioral, psychological, and physiological levels of observation. By performing slow, coordinated movements in harmony with specific breathing rhythms and techniques, MBE not only affects the memory, but also demands multiple high-order cognitions (e.g., perceptual speed, visual-spatial ability, attention, multitasking, and planning) to maintain their postural stability (20). A study on tai chi has provided evidence for its comparable effects on cognitive function and emotion in comparison with swimming, running, or square dancing (21). This impact is supported by studies that associate functional changes with neurophysiological mechanisms, such as increased brain-derived neurotrophic factor levels (22). Studies that connect plasticity in brain morphology and function, including processes central to executive function, which influence attention and memory, provide additional evidence of the far-reaching effects of MBEs $(15,17,23,24)$.

\section{Positive Effects of MBE on SUD}

According to a number of studies, different MBEs are reported to have positive impacts on some aspects that are severely influenced by SUD $(25,26)$. Qi gong meditation contributes positively to addiction treatment outcomes, and meditative therapy may be more attractive for female drug abusers than for males (27). In a study report, heroin users that were treated with qi gong seemed to have an accelerated detoxification, increased immune function, and improved oxygen metabolism, which were beneficial if they persisted in qi gong practice (28).

As a form of MBE, yoga is also used as a therapy of SUD and is reported to have certain positive effects (29). A 12-weeks yoga intervention can reduce substance intake, relieve the stress of SUD, and support individuals with SUD in getting back to normal life (30). In addition, considerable studies have demonstrated the positive effects of yoga on patients with SUD of opium, heroin, alcohol, and tobacco, including the improvement of the bodymind environment, depressive symptoms, emotion status, and decreased craving (31-34). Notably, most results of these studies indicate the amelioration of life quality after yoga exercise.

Mindfulness meditation may be another important approach to treat addiction (35). A review showed that after mindfulness meditation training, individuals' substance craving would decrease (36), and after 8 weeks of training, the risk of relapse would significantly reduce (37). This training approach improves the executive functions in adolescents with MA use disorders (38). Emerging evidence has shown that mindfulness meditation can treat and prevent SUD and other behavioral disorders by increasing the activity in areas of the brain involved in mood regulation (39).

Compared with other MBE, tai chi emphasizes the coordination of the body, breathing, and mind, and as a potentially effective exercise method to improve brain health and slow down brain aging, tai chi is attracting increasing attention (40). The effectiveness of tai chi in improving cognitive functions is reported in previous studies (41). Meanwhile, several studies suggest its affirmative impact on the body and mind of patients suffering from SUD, including enhanced inhibitory control and reduced craving $(42,43)$. A 4 -years follow-up study reported that only $9.5 \%$ of the individuals using amphetamine in the tai chi 
intervention group relapsed after intervention and $26.3 \%$ in the normal treatment group (44). Another study showed that tai chi could improve the quality of life and balance of amphetamine users (45).

Tai chi is a safe and acceptable exercise for individuals suffering from SUD. However, individuals with SUD in Shanghai Mandatory Detoxification and Rehabilitation Centers (SMDRC) often complain about the difficulty of learning and practicing tai chi sequences, particularly for those who entered SMDRC $<3$ months earlier. The Shanghai Drug Administration organizes a team to design an $\mathrm{MBE}$ and provide a safe and effective exercise for the new patients in SMDRC, which can be beneficial for individuals with SUD, physically and mentally. The MBE, also known as healthy mind exercise, is composed of tai chi, qi gong, and yoga. The criteria for the MBE is that it must be easy to learn, with low to moderate physical intensity. It is tailor-made for individuals with SUD in SMDRC who are sedentary with poor physical and cognitive functions. MBEs aim to improve participants' fitness, enhance the function of the motor and cardiovascular systems, and help participants to develop a satisfactory living habit and attitude after the intervention. However, related references that compare MBE with conventional treatment for the rehabilitation or treatment of individuals with SUD are limited, and the effects are unclear. Therefore, this experiment aimed to compare the physical fitness and mental effects of MBE intervention on individuals with SUD with that of the conventional exercise (CE) treatment in SMDRC.

\section{MATERIALS AND METHODS}

\section{Study Design}

This study was a single-blind (assessor-blind), 6-months randomized control trial. Participants were individuals with SUD randomly allocated to the MBE or CE group. Written informed consent was received from all participants, and the trial was approved by the Institutional Review Board of Shanghai University of Sport in accordance with the Declaration of Helsinki.

\section{Setting}

The trial was conducted in SMDRC, and participants of both groups received the same amount of intervention sessions that were organized on a basketball field under fair weather or in an indoor hall during rainy weather. Two well-trained Chinese traditional sport masters instructed the $\mathrm{MBE}$ in the MBE group, and experienced instructors from SMDRC provided conventional rehabilitation methods to the CE group. Experienced researchers conducted the assessment of fitness function and quality of life at baseline and after 3 and 6 months.

\section{Participants}

A total of 100 male individuals with SUD voluntarily participated in the trial, and they were randomly assigned to the MBE group $(n=50)$ and CE group $(n=50)$. At the time of recruitment, these individuals received drug withdrawal treatment at SMDRC. The inclusion criteria comprised voluntary individuals who were (1) aged 18 years or above, (2) reported to be amphetamine users, and (3) had no severe medical conditions that would preclude their participation in physical activities. The exclusion criteria consisted of (1) diagnosis of Axis I psychiatric disorders in addition to SUD, (2) medical or neurological illnesses or trauma that affected the central nervous system, and (3) undergoing pharmacological treatment with psychotropic medications.

The participants in the MBE group had an average age of 32 \pm 5 years, height of $172.7 \pm 5.6 \mathrm{~cm}$, weight of $74.5 \pm 11 \mathrm{~kg}$, and years of drug abuse of $9.42 \pm 5.29$. In addition, the participants in the CE group had an average age of $30 \pm 5$ years, height of $174.0 \pm 6.0 \mathrm{~cm}$, weight of $75.4 \pm 17.3 \mathrm{~kg}$, and years of drug abuse of $9.00 \pm 5.41$ years. No significant difference in age, height, and weight was observed between the two groups $(p>0.05)$ at the beginning of the experiment.

\section{Outcome Measures}

Outcome measures were obtained to verify the changes in physical fitness and mental health amongst the participants as a result of the interventions. Fitness with health-related and skill-related components involved day-to-day activities. Health-related fitness included aerobic fitness, muscular fitness, flexibility, and body composition (46). According to the Manual and Standard of Chinese National Physical Fitness Evaluation (MSCNPFE), physical fitness included body shape, physiological function, and fitness tests (47). In this study, the physical fitness test strictly followed the instruction of MSCNPFE. Mental health was defined by WHO as a state of well-being, in which an individual could realize his or her own abilities, cope with the everyday tasks and normal stresses of life, work productively, and make a contribution to the community (48). The mental health test was performed using the questionnaire of quality of life for addicted abusers (QOL-DA).

\section{Primary Outcome: Fitness Evaluation}

Measurements were performed every morning at the same time. Blood pressure (BP) was measured under standardized conditions prior to other tests: participants were asked to rest for $5 \mathrm{~min}$ and to stop taking caffeine or tobacco products within the preceding $30 \mathrm{~min}$. Body composition and body mass indexes (BMI) were measured with Omron HBF-305. A balance test was performed standing on one leg with eyes closed. A sport watch was used to record the duration of the balance test. A progressive aerobic cardiovascular endurance run (PACER) was carried out to measure the aerobic capacity of subjects following standardized procedures. The participants ran from one marker to another marker set $20 \mathrm{~m}$ apart whilst keeping pace with a prerecorded cadence. The cadence was set to music and increased every minute. Participants were instructed to keep up with the cadence for as long as possible. The test was terminated when a participant failed to reach the appropriate marker in the allotted time two times or could no longer maintain the pace. The number of laps completed was recorded $(49,50)$. The heart rate was monitored during the PACER test with a heart-rate monitor system (ALA COACH, Tai Wan). Subjects were required to wear a heart-rate strap on the chest, and the heart rate of each subject was transmitted to ALA COACH after the test. 


\section{Secondary Outcome: QOL-DA}

The QOL-DA questionnaire was developed by Chong-hua Wan in 1997 for drug-dependent patients in China. It consists of 40 items that measure four scales, including physiology (nine items; e.g., "do you feel lack of energy," "do you have difficulty doing things"), psychology (nine items; "do you feel lonely," "do you feel depressed"), society (11 items; "do you feel a lack of safety," "are you adaptable to the environment"), and symptoms (11 items; "have you had diarrhea," "have you had short breath"), and one independent item of self-evaluated health status (item 41). These items were rated on a five-point Likert scale. The scores from the four scales were calculated by the corresponding endorsed item scores that ranged from 9 to 45 (physiology and psychology) and from 11 to 55 (society and symptoms) $(51,52)$.

\section{Intervention}

\section{Experimental Group (MBE)}

Based on the physical characteristics of individuals with SUD in SMDRC, movements were selected from qi gong, tai chi, and yoga. The intensity, difficulty, and duration of exercises and practice space were considered. Each section of MBE included acupoint massage of traditional Chinese medicine to dredge meridians, stretch the body, and relieve muscle tension. Movements were in harmony with breathing, and practicing this $\mathrm{MBE}$ involved both physical function and mental elements. The form was composed of nine movements with four repetitions for each movement. The whole form was about $10 \mathrm{~min}$. Two repetitions were performed in each exercise session. The exercise was practiced three times a day, once in the morning, afternoon, and evening. The exercise intensity was 3.5 METs, and the average heart rate was $100 \mathrm{bpm}$ measured on four healthy college students with K4B2 and Polar Team Pro heart-rate monitors prior to this study, which corresponded to a low to moderate intensity.

\section{Control Group (CE)}

The control group was assigned to participate in recreational activities, which included $5 \mathrm{~min}$ of recreational activities (the ninth Guang Bo $\mathrm{Ti}$ Cao), $5 \mathrm{~min}$ of gesture language exercises, and self-study as recommended by the Shanghai Drug Administration. The duration of the intervention in the control group was similar to that of the MBE. The participants in the CE group had the same exercise frequency, intensity, duration, and exercise time as those in the MBE group.

\section{Randomization}

For this study, a total of 100 male illicit drug abusers were selected from SMDRC, coded as 01, 02, 03, ... The participants were randomly divided into two groups: 50 in the experimental group and 50 in the control group. The randomized numbers were generated using EXCEL for treatment observation.

\section{Statistics}

A Pearson chi-squared test was applied for categorical variables of demography, and an independent sample $t$-test was applied for continuous variables at the baseline comparison of QOLDA and fitness. The Pearson chi-squared test and independent sample $t$-test were used to compare the demographic and clinical characteristic differences of the two groups at baseline.

A two-way repeated measure analysis of variance (ANOVA) was performed to test whether the treatments were different after 3 and 6 months. Time (baseline, 3 and 6 months) was the within-group factor; groups (MBE and $\mathrm{CE}$ ) were the betweengroup factors, and year of drug dependence was the covariate. A post-hoc test with Bonferroni correction was used to identify the group that showed difference when the ANOVA showed a significant interaction. Effect size was used with the partial eta square as $\eta^{2}$. Statistical analyses were performed using SPSS 19.0 (Chicago, USA).

Data were reported as the mean values (plus SD), and the significance level was set to $p<0.05$. The interpretation of the eta square followed the rule of thumb by Cohen (53) with $>0.01$ (small), $>0.06$ (medium), and $>0.14$ (large).

\section{RESULTS}

The demographic data showed no statistically significant difference between the MBE and CE groups with regard to educational level, occupation, marital status, type of drug used, and duration of substance dependence $(p>0.05)$. In this study, the age of participants was between 20 and 40 years, and most of them were young. In addition, most of the participants were bachelors or divorced. The majority of the participants were unemployed. In both groups, $70-80 \%$ of the subjects had been users of MA (Table 1).

Six subjects in the MBE group and six subjects in the CE group dropped out during the intervention (Figure 1).

At baseline, no statistically significant differences were observed between the groups with regard to the physiological and physical fitness outcomes and scores of QOL-DA. The systolic pressure (SBP) in both groups was considered as elevated $\mathrm{BP}$ because the SBP was over $120 \mathrm{mmHg}$ (Table 2).

\section{Physiological Outcomes}

Statistically significant differences were found in the time $\times$ group interaction after 6 months regarding BMI $\left[F_{(2,166)}=3.99\right.$, $\left.p<0.05, \eta^{2}=0.046\right]$, systolic blood pressure $(\mathrm{SBP})\left[F_{(2,166)}\right.$ $\left.=11.77, p<0.01, \eta^{2}=0.124\right]$, diastolic blood pressure (DBP) $\left[F_{(2,166)}=8.96, p<0.01, \eta^{2}=0.097\right]$, pulse $\left[F_{(2,166)}=7.82, p<\right.$ $\left.0.01, \eta^{2}=0.086\right]$, and vital capacity $\left[F_{(2,166)}=3.08, p<0.05, \eta^{2}\right.$ $=0.036]$. The post-hoc analyses further revealed a significantly lower mean \pm Std of SBP in the MBE group than that in the CE group (122.27 \pm 1.98 vs. $128.78 \pm 2.02 \mathrm{mmHg} ; p=0.024)$. However, the vital capacity was significantly lower in the MBE group than that in the CE group (3006.55 \pm 74.33 vs. $3222.64 \pm$ $76.09 \mathrm{ml}$ ) after 6 months (Figure 2).

\section{Physical Fitness Outcomes}

Statistically significant differences were found in the time $x$ group interaction after 6 months with regard to sit-and-reach $\left[F_{(2,166)}=13.85, p<0.01, \eta^{2}=0.143\right]$, PACER $\left[F_{(2,166)}=15.05\right.$, $\left.p<0.01, \eta^{2}=0.165\right]$, and heart rate during the PACER test $\left[F_{(2,166)}=35.51, p<0.01, \eta^{2}=0.328\right]$. Post-hoc analyses showed that the MBE group had a significantly higher mean \pm Std laps 
TABLE 1 | Demography of individuals with substance use disorder $(N=100)$.

\begin{tabular}{|c|c|c|c|c|c|c|}
\hline \multicolumn{2}{|c|}{ Contents } & \multicolumn{2}{|c|}{$\begin{array}{l}\text { Mind-body exercise } \\
\qquad(N=50)\end{array}$} & \multicolumn{2}{|c|}{$\begin{array}{l}\text { Conventional exercise } \\
\qquad(N=50)\end{array}$} & \multirow[t]{2}{*}{$\mathbf{P}$} \\
\hline & & $N$ & Percent (\%) & $N$ & Percent (\%) & \\
\hline \multirow[t]{3}{*}{ Age } & 20-30 years & 20 & 40 & 27 & 54 & 0.88 \\
\hline & $31-40$ years & 29 & 58 & 22 & 44 & \\
\hline & $41-50$ years & 1 & 2 & 1 & 2 & \\
\hline \multirow[t]{4}{*}{ Marital status } & Married & 16 & 32 & 11 & 22 & 0.96 \\
\hline & Single & 25 & 50 & 29 & 58 & \\
\hline & Divorced & 9 & 18 & 10 & 20 & \\
\hline & Widowed & 0 & 0 & 0 & 0 & \\
\hline \multirow[t]{5}{*}{ Education } & Elementary & 8 & 16 & 6 & 12 & 0.19 \\
\hline & Middle school & 26 & 52 & 25 & 50 & \\
\hline & $\begin{array}{l}\text { High school } \\
\text { or equivalent }\end{array}$ & 9 & 18 & 12 & 24 & \\
\hline & Junior college & 7 & 14 & 6 & 12 & \\
\hline & $\begin{array}{l}\text { College level } \\
\text { or higher }\end{array}$ & 0 & 0 & 1 & 2 & \\
\hline \multirow[t]{8}{*}{ Occupation } & Unemployed & 26 & 52 & 21 & 42 & 0.67 \\
\hline & Owner & 7 & 14 & 10 & 20 & \\
\hline & Service & 0 & 0 & 1 & 2 & \\
\hline & Farmer & 1 & 2 & 0 & 0 & \\
\hline & Worker & 5 & 10 & 1 & 2 & \\
\hline & Driver & 4 & 8 & 1 & 2 & \\
\hline & Staff & 4 & 8 & 7 & 14 & \\
\hline & Others & 3 & 6 & 8 & 16 & \\
\hline \multirow[t]{8}{*}{ Type of drug } & Heroin & 16 & 32 & 13 & 26 & 1.25 \\
\hline & Methamphetamine & 37 & 74 & 41 & 82 & \\
\hline & Ketamine & 5 & 10 & 2 & 4 & \\
\hline & Cocaine & 1 & 2 & 0 & 0 & \\
\hline & Ecstasy & 4 & 8 & 2 & 4 & \\
\hline & Marijuana & 2 & 4 & 2 & 4 & \\
\hline & $\begin{array}{l}\text { Times of } \\
\text { treatments }\end{array}$ & \multicolumn{2}{|c|}{$1.94 \pm 1.50$} & \multicolumn{2}{|c|}{$1.48 \pm 0.86$} & 0.56 \\
\hline & $\begin{array}{l}\text { Years of drug } \\
\text { dependents } \\
\text { (years) }\end{array}$ & \multicolumn{2}{|c|}{$9.42 \pm 5.29$} & \multicolumn{2}{|c|}{$9.00 \pm 5.41$} & 0.49 \\
\hline
\end{tabular}

of PACER (12.89 \pm 0.42 vs. $11.47 \pm 0.47 ; p=0.029)$ and a significantly lower heart rate $(105.38 \pm 1.65$ vs. $119.30 \pm 1.78$ bpm; $p<0.001)$ than the CE group during the PACER test.

\section{Mental Outcomes}

Statistically significant differences were also observed between the two groups with regard to QOL-DA scores: physiology $\left[F_{(2,172)}=10.47, p<0.01, \eta^{2}=0.11\right]$, psychology $\left[F_{(2,172)}=\right.$ 9.82, $\left.p<0.01, \eta^{2}=0.102\right]$, symptom $\left[F_{(2,172)}=6.50, p<\right.$ $\left.0.01, \eta^{2}=0.07\right]$, and society $\left[F_{(2,172)}=15.08, p<0.01, \eta^{2}\right.$ $=0.149]$, and the total score of QOL-DA $\left[F_{(2,172)}=16.13\right.$, $\left.p<0.01, \eta^{2}=0.158\right]$ was increased in the MBE group, whereas the scores in the CE group decreased after 6 months (Table 3).

\section{DISCUSSION}

In this study, we compared the physical and mental effects of an MBE intervention with the conventional rehabilitation approach. The participants in the MBE group had statistically better physical function and mental outcomes than those in the CE group. Moreover, the MBE group showed better effects on BMI, SBP, pulse, and PACER test. The findings indicated that the MBE intervention might be beneficial for weight control and hypertension.

\section{Physical Fitness Benefit From the MBE Relationship Between Weight Gain and Aerobic Capacity}

In general, weight gain in illicit drug abusers is interpreted as a positive treatment outcome of amphetamine (54) because one 


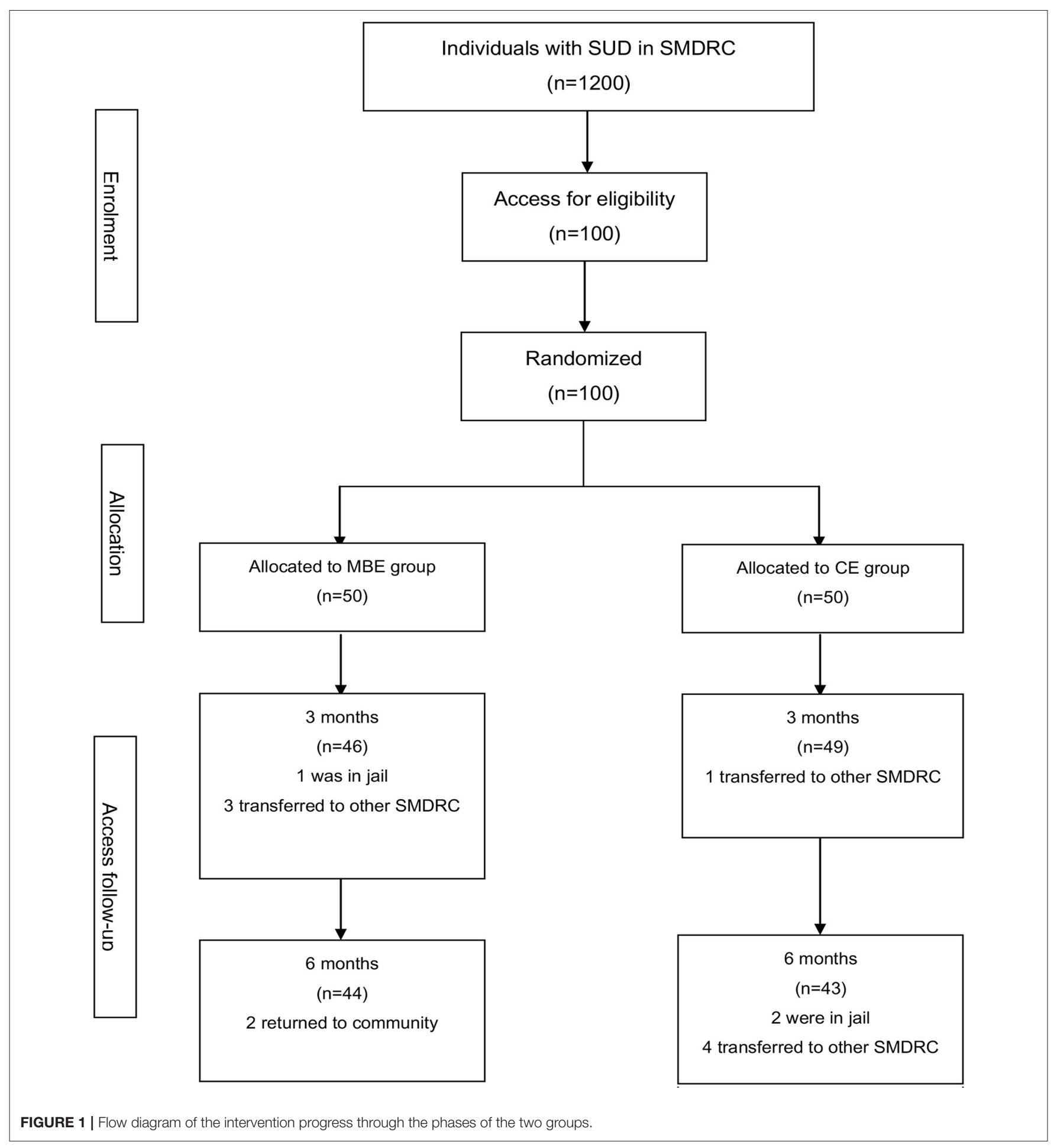

of the effects of MA is suppressing appetite $(55,56)$. Based on related research, average BMI was significantly lower amongst MA abusers compared with the age-matched healthy controls reported by a survey in China (57). Methadone treatment and MA compulsory treatment were associated with weight gain $(45,58)$. In particular, fat mass increased after a certain period of treatment once the effects of the illicit drugs on appetite suppression and metabolism were removed (59). The statistically significant weight loss measured by the BMI decreased in the MBE group, but no changes were found in the CE group, indicating that the MBE might be a gentle and potential exercise to control weight gain during the treatment of SUD. MBE was suitable for those who do not want to participate in procedures with vigorous exercises. 
TABLE 2 | Physiological and physical fitness outcome comparison between the MBE and CE groups at the baseline.

\begin{tabular}{|c|c|c|c|c|}
\hline Items & $\begin{array}{l}\text { Mind-body exercise } \\
\qquad(n=50)\end{array}$ & $\begin{array}{l}\text { Conventional exercise } \\
\qquad(n=50)\end{array}$ & $T$ & $P$-value \\
\hline BMl $\left(\mathrm{kg} / \mathrm{m}^{2}\right)$ & $24.91 \pm 3.26$ & $25.52 \pm 3.89$ & -0.860 & 0.392 \\
\hline Body fat (\%) & $23.41 \pm 4.56$ & $23.37 \pm 4.34$ & -0.043 & 0.966 \\
\hline Systolic (mmHg) & $128.19 \pm 13.88$ & $129.54 \pm 17.51$ & -0.424 & 0.673 \\
\hline Diastolic (mmHg) & $79.67 \pm 12.44$ & $76.16 \pm 11.48$ & 1.458 & 0.148 \\
\hline Pulse (bpm) & $75.58 \pm 14.57$ & $73.65 \pm 12.20$ & 0.712 & 0.478 \\
\hline Vital capacity (ml) & $3059.20 \pm 721.19$ & $3128.78 \pm 841.44$ & -0.442 & 0.659 \\
\hline Fundamental metabolize (kcal) & $1674.20 \pm 163.18$ & $1723.63 \pm 202.21$ & -1.340 & 0.183 \\
\hline Sit-and-reach (cm) & $5.09 \pm 8.07$ & $7.28 \pm 7.75$ & -1.379 & 0.171 \\
\hline One-leg stand with eyes closed (s) & $30.38 \pm 24.03$ & $34.22 \pm 29.47$ & -0.707 & 0.481 \\
\hline
\end{tabular}

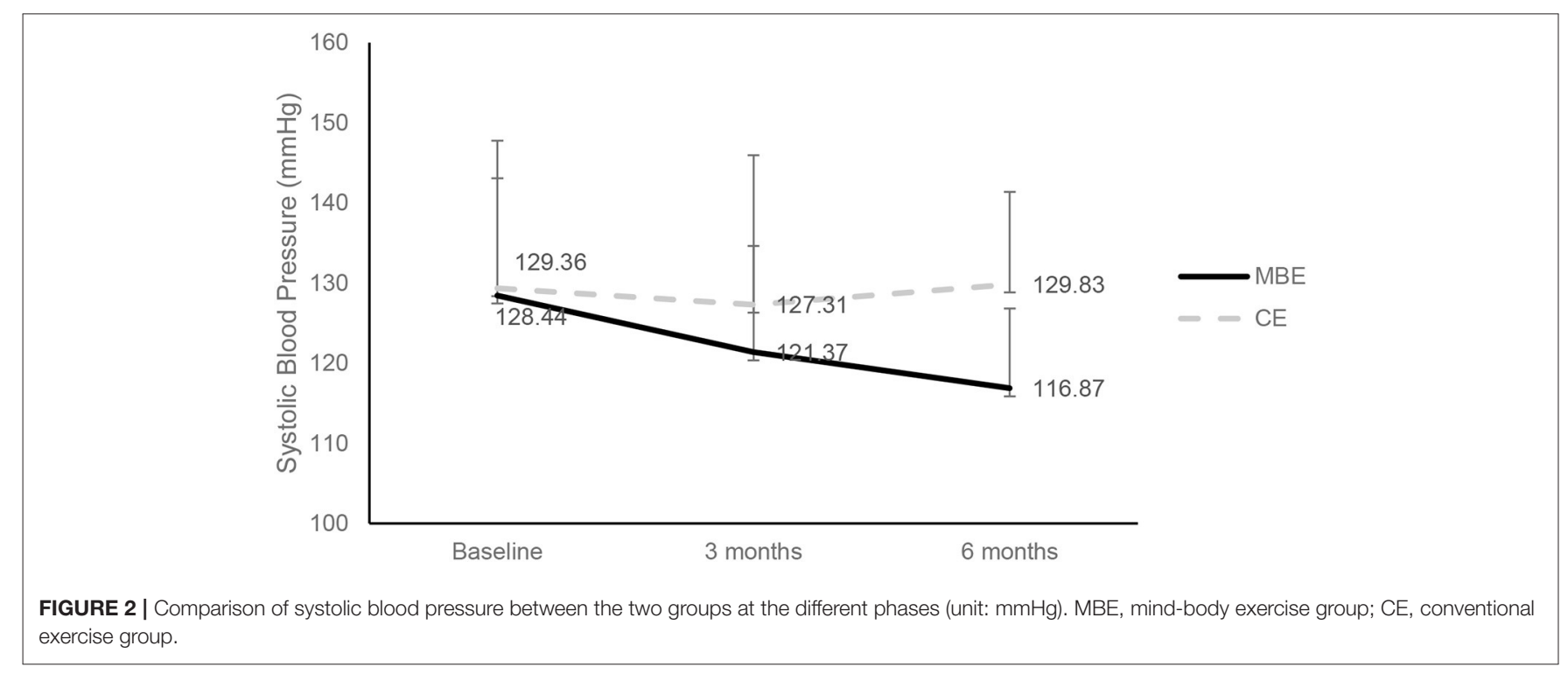

Tai chi, qi gong, and yoga were assumed to have beneficial effects on the cardio-respiratory function of adults at different ages (60-62). In our study, aerobic endurance gradually decreased in both groups. This result was consistent with our previous study where the laps of the PACER test decreased in the experimental and control groups (44). However, the PACER test in the MBE group gradually decreased compared with the CE group. The sedentary behavior of subjects in mandatory detoxification and rehabilitation centers (MDRC) might raise the risk of cardiovascular diseases, such as hypertension and psychological diseases, such as depression because of weight gain. Physical activities are recommended for these subjects because sedentary behavior increased the prevalence of getting into MDRC. The results showed that MBE could alleviate the deterioration of endurance capacity amongst individuals with SUD and protect against weight gain during rehabilitation in MDRC.

Most movements in $\mathrm{MBE}$ were composed of elements of qi gong. As reported in many studies, qi gong has a number of potential advantages for respiratory function promotion through the action of qi gong forms with diaphragmatic muscle activity for deep breathing. By making the human thorax fully widen and narrow, the respiratory muscles are fully trained whilst practicing these movements. In addition, the combination of chest and abdominal breathing increased the activity of the diaphragm and abdominal muscles, thereby regulating the intercostal muscles and respiratory function, causing an increase in pulmonary ventilation $(63,64)$. The positive effects of breathing on the regulation of emotions (65) and cognitive functions, particularly with lower frequency, as enforced by qi gong, were reported and seemed to play a role in mindfulness training $(66,67)$. Although the post-hoc analysis revealed that the vital capacity in the MBE group after 6 months was lower than that in the CE group, the outcome of vital capacity in the MBE group was found to increase slightly from $2,995 \mathrm{ml}$ at baseline to $3,151 \mathrm{ml}$ after 6 months, and the result in the CE group was decreased from $3,216 \mathrm{ml}$ at baseline to $3,181 \mathrm{ml}$ after 6 months.

\section{BP and Pulse}

Previous systematic reviews indicated that TC might be safe and effective in reducing BP, improving aerobic capacity, and exercising tolerance for patients with cardiovascular conditions 
TABLE 3 | Comparison of the two groups at baseline, 3 and 6 months by ANOVA repeat measures.

\begin{tabular}{|c|c|c|c|c|c|c|c|c|}
\hline & \multicolumn{3}{|c|}{ MBE $(N=44)$} & \multicolumn{3}{|c|}{ CE $(N=43)$} & \multirow{2}{*}{ Time $\times$ Group (F) } & \multirow[t]{2}{*}{ Eta } \\
\hline & Baseline & 3 Months & 6 Months & Baseline & 3 Months & 6 Months & & \\
\hline \multicolumn{9}{|l|}{ MENTAL OUTCOMES } \\
\hline Physiology (PH) & $32.68(6.83)$ & $34.20(5.63)$ & $34.86(6.67)$ & $33.20(6.54)$ & $32.66(7.03)$ & $27.41(8.81)$ & $10.47^{\star \star}$ & 0.11 \\
\hline Psychology (PS) & $32.36(8.50)$ & $35.86(6.60)$ & $36.25(7.79)$ & $33.77(7.38)$ & $33.80(8.43)$ & $27.73(10.44)$ & $9.82^{\star \star}$ & 0.102 \\
\hline Symptom (ST) & $47.86(6.82)$ & $48.27(7.10)$ & $48.23(6.33)$ & $47.70(6.91)$ & $48.39(7.18)$ & $42.43(8.37)$ & $6.50^{\star \star}$ & 0.07 \\
\hline Society (SO) & $38.25(6.34)$ & $38.77(7.77)$ & $41.73(6.06)$ & $39.45(6.84)$ & $39.89(6.69)$ & $34.61(7.94)$ & $15.08^{\star \star}$ & 0.149 \\
\hline Total score & $151.16(23.29)$ & $157.11(20.57)$ & $161.07(21.23)$ & $154.14(24.03)$ & $154.73(24.95)$ & $132.18(30.76)$ & $16.13^{\star \star}$ & 0.158 \\
\hline \multicolumn{9}{|l|}{ PHYSIOLOGICAL OUTCOMES } \\
\hline Mass (kg) & $74.74(11.46)$ & $72.70(11.78)$ & 71.09 (11.73) & $75.47(17.94)$ & $75.54(13.75)$ & $75.11(12.93)$ & 2.39 & 0.028 \\
\hline $\mathrm{BMl}\left(\mathrm{kg} / \mathrm{m}^{2}\right)$ & $25.10(3.37)$ & $24.40(3.42)$ & $23.61(3.46)$ & $25.69(3.95)$ & $25.03(4.00)$ & $24.80(3.86)$ & $3.99^{\star}$ & 0.046 \\
\hline Body fat (\%) & 23.85 (4.59) & $21.71(4.96)$ & $20.62(5.09)$ & $23.66(4.11)$ & $22.08(4.65)$ & $21.42(4.85)$ & 2.84 & 0.033 \\
\hline Systolic (mmHg) & $128.44(14.64)$ & 121.37 (13.24) & $116.87(9.97)$ & 129.36 (18.39) & $127.31(18.62)$ & $129.83(11.55)$ & $11.77^{\star \star}$ & 0.124 \\
\hline Diastolic (mmHg) & 79.87 (13.03) & $75.54(9.46)$ & $74.67(8.41)$ & $75.98(12.14)$ & $76.06(11.57)$ & $78.83(10.91)$ & $8.96^{\star \star}$ & 0.097 \\
\hline Pulse (bpm) & $75.02(14.82)$ & 70.60 (12.23) & $69.44(7.23)$ & 73.02 (12.10) & $65.34(8.71)$ & $72.52(10.64)$ & $7.82^{\star \star}$ & 0.086 \\
\hline Basic metabolism (kcal) & 1675.39 (168.48) & 1655.95 (173.86) & $1632.77(172.18)$ & 1728.71 (204.87) & $1699.29(203.74)$ & 1686.17 (197.99) & 0.82 & 0.01 \\
\hline Vital capacity (ml) & 2994.75 (659.25) & $2870.41(632.59)$ & 3150.89 (526.52) & 3216.12 (811.43) & 3275.05 (547.24) & 3180.52 (597.89) & $3.08^{\star}$ & 0.036 \\
\hline \multicolumn{9}{|l|}{ PHYSICAL FITNESS OUTCOMES } \\
\hline Sit-and-reach (cm) & $4.64(8.38)$ & $6.20(7.68)$ & $11.82(6.77)$ & $7.34(7.65)$ & $8.21(7.50)$ & $8.23(8.08)$ & $13.85^{\star \star}$ & 0.143 \\
\hline One-leg stand with eye closed(s) & $30.55(25.35)$ & $30.56(26.49)$ & $36.11(20.77)$ & $30.41(21.70)$ & $26.70(15.52)$ & $27.64(14.99)$ & 1.71 & 0.02 \\
\hline PACER (laps) & $16.05(5.39)$ & $14.23(4.32)$ & $8.37(3.51)$ & $18.19(3.70)$ & $11.83(4.73)$ & $4.39(1.44)$ & $15.05^{\star \star}$ & 0.165 \\
\hline Running hear rate (bpm) & $109.72(17.01)$ & $104.21(12.01)$ & 102.09 (11.99) & $107.70(13.13)$ & $123.41(15.27)$ & $126.95(11.86)$ & $35.51^{\star \star}$ & 0.328 \\
\hline
\end{tabular}

MBE, mind-body exercise; $C E$, conventional exercises; data presented as mean (SD); ${ }^{*} p<0.05$; ${ }^{* *} p<0.01$.

and risk factors (68-70). In that study, the BP and heart rate of individuals with SUD decreased in the MBE group, whereas no significant changes in $\mathrm{BP}$ and heart rate were found in the $\mathrm{CE}$ group. The SBP in the MBE group decreased to $11.57 \mathrm{mmHg}$, whereas no changes were found in the CE group. A reduction of $5 \mathrm{mmHg}$ might reduce the risk of hypertension-related diseases (71). The SBP and DBP changes in individuals with SUD were consistent with the findings from earlier studies $(44,45,60)$. Studies found that reductions in SBP and DBP were observed in several trials of qi gong interventions (72). A related study reported that the qi gong group showed a statistically significant improvement in ventilation functions, whereas no change was found in the control group after 10 weeks of practice (73). Tai chi, qi gong, and yoga MBEs using meditation, imagery, breathing, general relaxation, and stress reduction played active roles in the overall effects whilst practicing (74). The reduction of BP might stem from the enhancement of the parasympathetic tone and reduction of the sympathetic tone during the MBEs, such as relaxation training (75). Based on related studies, the low BP levels after MBE were compatible with the stabilization of the parasympathetic nervous system (PNS) and sympathetic nervous system (SNS) activities because BP has been shown to be directly linked to PNS and SNS activities $(73,75,76)$.

The results of the PACER test showed that the number of running laps in the MBE group and CE group continued to decrease. The number of running laps in the MBE group decreased from 16 laps at baseline to 8 laps after 6 months. On the contrary, the number of running laps in the CE group dropped from 18 laps at baseline to 4 laps after 6 months, showing a drop of 14 laps. Post-hoc analysis indicated that a highly significant difference could be observed between the PACER test results in the two groups. The PACER test results in both groups indicated that the aerobic endurance capacity of individuals with SUD continuously decreased, and it was hardly maintained amongst individuals with SUD in SMDRC. Therefore, more exercises that focused on improving the cardiovascular function were encouraged in MDRC.

The MBE group ran more laps than the CE group. In addition, the average heart rate in the MBE group was lower than that in the CE group after 6 months. The pulse rate test during the PACER test in the MBE group continued to decline from 110 bpm at baseline to $102 \mathrm{bpm}$ and decreased by $8 \mathrm{bpm}$ during the same time span. By contrast, the average heart rate in the $\mathrm{CE}$ group continued to increase over the duration of the experiment, from $108 \mathrm{bpm}$ at baseline to $127 \mathrm{bpm}$, showing an increase of $19 \mathrm{bpm}$ over 6 months. Combined with the decrease of BP, the results indicated that $\mathrm{MBE}$ could have a beneficial effect on the cardiovascular system.

\section{Mental Benefit From the MBE}

The scores of QOL-DA with regard to physiology, psychology, symptom, and societal function were significantly improved in the MBE group over 6 months, whereas these outcomes decreased in the CE group over time. Our findings were consistent with those of the previous study where MBE, such as tai chi was beneficial to SUD regarding the quality of life. 
The physical function and physiological changes with regard to the results of the mental function improvement and the scores of psychology, symptom, and society were not significantly improved in the MBE group, and such results were poor in the CE group. Consequently, MBE might help individuals with SUD in improving their quality of life.

\section{Limitations and Recommendations for Future Research}

This study has several limitations. Firstly, the results of PACER were strongly related to participant's momentary motivation and attitude. Consequently, in future studies, incentive tests should be conducted to motivate the subjects to try their best during $\mathrm{PE}$ tests, which required high tolerance. Secondly, moderateintensity continuous training or high-intensity interval training for improving aerobic capacity was not arranged because of the limited number of individuals with SUD who voluntarily participated in this study. Finally, considering that the study only included male individuals with SUD, whether gender difference might influence the physical fitness and mental effects remained unclear.

Further studies might continuously focus on the effects of exercise interventions on weight control of individuals with SUD because of the high risk of cardiovascular diseases caused by weight gain. Weight gain was a positive effect of abstinence because appetite suppression caused by illicit drug use was diminished, but the potential cardiovascular diseases brought on by inactivity might deteriorate the health of individuals with SUD.

\section{CONCLUSION}

Our findings indicate that $\mathrm{MBE}$ has better physical fitness and mental effects than the conventional physical rehabilitation method. This approach may help participants in maintaining their body weight, decreasing the deterioration of aerobic

\section{REFERENCES}

1. Colledge F, Gerber M, Pühse U, Ludyga S. Anaerobic exercise training in the therapy of substance use disorders: a systematic review. Front Psychiatry. (2018) 9:644-4. doi: 10.3389/fpsyt.2018.00644

2. Nock NL, Minnes S, Alberts JL. Neurobiology of substance use in adolescents and potential therapeutic effects of exercise for prevention and treatment of substance use disorders. Birth Defects Res. (2017) 109:171129. doi: 10.1002/bdr2.1182

3. Henry BL, Minassian A, van Rhenen M, Young JW, Geyer MA, Perry W. Effect of methamphetamine dependence on inhibitory deficits in a novel human open-field paradigm. Psychopharmacology (Berl). (2011) 215:697707. doi: 10.1007/s00213-011-2170-2

4. Neeki MM, Kulczycki M, Toy J, Dong F, Lee C, Borger R, et al. Frequency of methamphetamine use as a major contributor toward the severity of cardiomyopathy in adults $\leq 50$ years. Am. J. Cardiol. (2016) 118:5859. doi: 10.1016/j.amjcard.2016.05.057

5. Chen CK, Lin SK, Sham PC, Ball D, Loh EW, Hsiao CC, et al. Pre-morbid characteristics and co-morbidity of methamphetamine users with and without psychosis. Psychol Med. (2003) 33:1407-14. doi: 10.1017/S0033291703 008353 capacity, and alleviating the risk of cardiovascular diseases. The quality of life of individuals with SUD can be improved by continually practicing MBE after intervention.

\section{DATA AVAILABILITY STATEMENT}

The datasets generated for this study are available on request to the corresponding author.

\section{ETHICS STATEMENT}

The studies involving human participants were reviewed and approved by Shanghai University of Sport. The patients/participants provided their written informed consent to participate in this study.

\section{AUTHOR CONTRIBUTIONS}

DZ designed this study, analyzed the data, and wrote the manuscript. MJ conducted the exercise intervention, collected the data, and organized the measurement. DX study coordinating, study design, and research project advised. WS involved in the part of discussion and revised the manuscript. All authors contributed to the article and approved the submitted version.

\section{FUNDING}

This study was financially supported by the Shanghai Drug Administration and National Key Research and Development (2018YFC0807405).

\section{ACKNOWLEDGMENTS}

This study was supported by the staff of the Shanghai Gao Jing Mandatory Detoxification and Rehabilitation Center.
6. Kaye S, McKetin R, Duflou J, Darke S. Methamphetamine and cardiovascular pathology: a review of the evidence. Addiction. (2007) 102:1204-11. doi: 10.1111/j.1360-0443.2007.01874.x

7. Zhong N, Jiang $\mathrm{H}$, Du J, Zhao Y, Sun H, Xu D, et al. The cognitive impairments and psychological wellbeing of methamphetamine dependent patients compared with health controls. Prog Neuropsychopharmacol Biol Psychiatry. (2016) 69:31-7. doi: 10.1016/j.pnpbp.2016.04.005

8. Rong C, Jiang HF, Zhang RW, Zhang LJ, Zhang JC, Zhang J, et al. Factors associated with relapse among heroin addicts: evidence from a two-year community-based follow-up study in China. Int J Environ Res Public Health. (2016) 13:177. doi: 10.3390/ijerph13020177

9. Brensilver M, Heinzerling KG, Shoptaw S. Pharmacotherapy of amphetamine-type stimulant dependence: an update. Drug Alcohol Rev. (2013) 32:449-60. doi: 10.1111/dar.12048

10. Hallgren M, Vancampfort D, Schuch F, Lundin A, Stubbs B. More reasons to move: exercise in the treatment of alcohol use disorders. Front Psychiatry. (2017) 8:5. doi: 10.3389/fpsyt.2017.00160

11. Kwan M, Bobko S, Faulkner G, Donnelly P, Cairney J. Sport participation and alcohol and illicit drug use in adolescents and young adults: a systematic review of longitudinal studies. Addict Behav. (2014) 39:497506. doi: 10.1016/j.addbeh.2013.11.006 
12. Da Costa KG, Rachetti VS, Da Silva WQA, Cabral DAR, Machado DGD, Costa EC, et al. Drug abusers have impaired cerebral oxygenation and cognition during exercise. PLoS ONE. (2017) 12:e0188030. doi: 10.1371/journal.pone.0188030

13. Seifert T, Brassard P, Wissenberg M, Rasmussen P, Nordby P, Stallknecht $\mathrm{B}$, et al. Endurance training enhances BDNF release from the human brain. Am J Physiol Regul Integr Compar Physiol. (2010) 298:R3727. doi: 10.1152/ajpregu.00525.2009

14. Mustroph ML, Stobaugh DJ, Miller DS, DeYoung EK, Rhodes JS. Wheel running can accelerate or delay extinction of conditioned place preference for cocaine in male C57BL/6J mice, depending on timing of wheel access. Eur J Neurosci. (2011) 34:1161-9. doi: 10.1111/j.1460-9568.2011.07828.x

15. Acevedo BP, Pospos S, Lavretsky H. The neural mechanisms of meditative practices: novel approaches for healthy aging. Curr Behav Neurosci Rep. (2016) 3:328-39. doi: 10.1007/s40473-016-0098-x

16. NCCIH. Complementary, Alternative, or Integrative Health: What's In a Name? (2018). Available online at: https://www.nccih.nih.gov/health/ complementary-alternative-or-integrative-health-whats-in-a-name

17. Innes KE, Selfe TK, Vishnu A. Mind-body therapies for menopausal symptoms: a systematic review. Maturitas. (2010) 66:135-49. doi: 10.1016/j.maturitas.2010.01.016

18. Jouper, J, Hassmen P. Exercise intention, age and stress predict increased Qigong exercise adherence. J Bodyw Mov Ther. (2009) 13:205-11. doi: 10.1016/j.jbmt.2008.08.002

19. Lavretsky H, Alstein LL, Olmstead RE, Ercoli LM, Riparetti-Brown M, Cyr NS, et al. Complementary use of Tai Chi Chih augments escitalopram treatment of geriatric depression: a randomized controlled trial. Am J Geriatr Psychiatry. (2011) 19:839-50. doi: 10.1097/JGP.0b013e31820ee9ef

20. Zou LY, Loprinzi PD, Yeung AS, Zeng N, Huang T. The beneficial effects of mind-body exercises for people with mild cognitive impairment: a systematic review with meta-analysis. Archiv Phys Med Rehabil. (2019) 100:155673. doi: 10.1016/j.apmr.2019.03.009

21. Zhang X, Ni X, Chen P. Study about the effects of different fitness sports on cognitive function and emotion of the aged. Cell Biochem Biophys. (2014) 70:1591-6. doi: 10.1007/s12013-014-0100-8

22. Sungkarat S, Boripuntakul S, Kumfu S, Lord SR, Chattipakorn N. Tai Chi improves cognition and plasma BDNF in Older adults with mild cognitive impairment: a randomized controlled trial. Neurorehabil Neural Repair. (2018) 32:142-9. doi: 10.1177/1545968317753682

23. Wahbeh H, Elsas SM, Oken BS. Mind-body interventions: applications in neurology. Neurology. (2008) 70:23218. doi: 10.1212/01.wnl.0000314667.16386.5e

24. Wayne PM, Walsh JN, Taylor-Piliae RE, Wells RE, Papp KV, Donovan NJ, et al. Effect of Tai Chi on cognitive performance in older adults: systematic review and meta-analysis. J Am Geriatr Soc. (2014) 62:2539. doi: 10.1111/jgs.12611

25. Liu F, Cui JB, Liu X, Chen KW, Chen XR, Li R. The effect of Tai Chi and Qigong exercise on depression and anxiety of individuals with substance use disorders: a systematic review and meta-analysis. BMC Complement Med Ther. (2020) 20:11. doi: 10.1186/s12906-020-02967-8

26. Brewer JA, Bowen S, Smith JT, Marlatt GA, Potenza MN. Mindfulnessbased treatments for co-occurring depression and substance use disorders: what can we learn from the brain? Addiction. (2010) 105:1698-706. doi: 10.1111/j.1360-0443.2009.02890.x

27. Chen KW, Comerford A, Shinnick P, Ziedonis DM. Introducing Qigong meditation into residential addiction treatment: a pilot study where gender makes a difference. J Altern Complement Med. (2010) 16:87582. doi: 10.1089/acm.2009.0443

28. Li M, Chen K, Mo Z. Use of qigong therapy in the detoxification of heroin addicts. Altern Ther Health Med. (2002) 8:1-8.

29. Khanna S, Greeson JM. A narrative review of yoga and mindfulness as complementary therapies for addiction. Complement Ther Med. (2013) 21:244-52. doi: 10.1016/j.ctim.2013.01.008

30. Wimberly AS. How yoga impacts the substance use of people living with HIV who are in reentry from prison or jail: a qualitative study. Complement Ther Med. (2019) 47:102074. doi: 10.1016/j.ctim.2019.03.022

31. Devi, Jiteswori N, Singh TB, Subramanya P. Effect of Yoga on Depression and Quality of Life in Drug Abusers (2014).
32. Dhawan A, Chopra A, Jain R, Yadav D, Vedamurthachar. Effectiveness of yogic breathing intervention on quality of life of opioid dependent users. Int $J$ Yoga. (2015) 8:144-7. doi: 10.4103/0973-6131.154075

33. Shahab L, Sarkar BK, West R. The acute effects of yogic breathing exercises on craving and withdrawal symptoms in abstaining smokers. Psychopharmacology. (2013) 225:875-82. doi: 10.1007/s00213-012-2876-9

34. Zhuang SM, An SH, Zhao Y. Yoga effects on mood and quality of life in Chinese women undergoing heroin detoxification: a randomized controlled trial. Nurs Res. (2013) 62:260. doi: 10.1097/NNR.0b013e318292379b

35. Hlzel BK, Lazar SW, Gard T, Schuman-Olivier Z, Ott U. How does mindfulness meditation work? Proposing mechanisms of action from a conceptual and neural perspective. Perspect Psychol Sci. (2011) 6:53759. doi: $10.1177 / 1745691611419671$

36. Brewer JA, Elwafi HM, Davis JH. Craving to quit: psychological models and neurobiological mechanisms of mindfulness training as treatment for addictions. Psychol Addict Behav J Soc Psychol Addict Behav. (2013) 27:36679. doi: $10.1037 / \mathrm{a} 0028490$

37. Bowen S, Witkiewitz K, Clifasefi SL, Grow J, Chawla N, Hsu SH, et al. Relative efficacy of mindfulness-based relapse prevention, standard relapse prevention, and treatment as usual for substance use disorders: a randomized clinical trial. JAMA Psychiatry. (2014) 71:547. doi: 10.1001/jamapsychiatry.2013.4546

38. Goradel JA, Imani S, Nejati V, Fathabadi J. Mindfulness-based substance abuse treatment (MBSAT) improves executive functions in adolescents with substance use disorders. Neurol Psychiatry Brain Res. (2019) 34:2134. doi: 10.1016/j.npbr.2019.08.002

39. Tang YY, Tang R, Posner MI. Mindfulness meditation improves emotion regulation and reduces drug abuse. Drug Alcohol Depend. (2016) 163:S138. doi: 10.1016/j.drugalcdep.2015.11.041

40. Loprinzi PD, Herod SM, Cardinal BJ, Noakes TD. Physical activity and the brain: a review of this dynamic, bi-directional relationship. Brain Res. (2013) 1539:95-104. doi: 10.1016/j.brainres.2013.10.004

41. Bherer L, Erickson KI, Liu-Ambrose T. A review of the effects of physical activity and exercise on cognitive and brain functions in older adults. J Aging Res. (2013) 2013:1-8. doi: 10.1155/2013/657508

42. Mingzhen Z. Effect of Tai Chi Rehabilitation Exercise on Heart Rate Variability and Related Indexes of Female Methamphetamine Dependent Indualvidus. Shanghai: Shanghai University of Sport (2018).

43. Zhilei Z. Effect of Taijiquan Exercise Program on Rehabilitation of Amphetamine Doping Dependents. Shanghai: Shanghai University of Sport (2019).

44. Zhu D, Dai G, Xu D, Xu X, Geng J, Zhu W, et al. Long-term effects of Tai Chi intervention on sleep and mental health of female individuals with dependence on amphetamine-type stimulants. Front Psychol. (2018) 9:1476. doi: 10.3389/fpsyg.2018.01476

45. Zhu D, Xu D, Dai G, Wang F, Xu X, Zhou D. Beneficial effects of Tai Chi for amphetamine-type stimulant dependence: a pilot study. Am J Drug Alcohol Abuse. (2016) 42:469-78. doi: 10.3109/00952990.2016.1153646

46. Bushman B. ACSM's Complete Guide to Fitness \& Health. Champaign, IL: Human Kinetics (2011)

47. Jiang CM, Yu DZ, Cai R. Study of national physical fitness evaluation standard. Sport Sci. (2004):33-6. doi: 10.16469/j.css.2004.03.011

48. WHO. Mental Health: Strengthening Our Response. (2018). Available online at: https://www.who.int/en/news-room/fact-sheets/detail/mental-healthstrengthening-our-response

49. Marques A, Santos R, Ekelund U, Sardinha LB. Association between physical activity, sedentary time, and healthy fitness in youth. Med Sci Sports Exerc. (2015) 47:575-80. doi: 10.1249/MSS.0000000000 000426

50. Mahar MT, Guerieri AM, Hanna MS, Kemble CD. Estimation of aerobic fitness from 20-m multistage shuttle run test performance. Am J Prev Med. (2011) 41:S117-23. doi: 10.1016/j.amepre.2011.07.008

51. Wan CH, Fang JQ, Jiang RS, Shen J, Jiang D, Tu X, et al. Development and validation of a quality of life instrument for patients with drug dependence: comparisons with SF-36 and WHOQOL-100. Int J Nurs Stud. (2011) 48:108095. doi: 10.1016/j.ijnurstu.2011.02.012

52. Zhou K, Zhuang G, Zhang H, Liang P, Yin J. Psychometrics of the short form 36 health survey version 2 (SF-36v2) and the quality of life scale for drug addicts (QOL-DAv2.0) in Chinese mainland 
patients with methadone maintenance treatment. PLoS ONE. (2014) 9: e79828. doi: 10.1371/journal.pone.0079828

53. Cohen, J. (1988). Statistical Power Analysis for the Behavioral Sciences, 2nd Edn. Hillsdale, NJ: Lawrence Erlbaum.

54. Shearer J, Darke S, Rodgers C, Slade T, van Beek I, Lewis J, et al. A double-blind, placebo-controlled trial of modafinil (200 $\mathrm{mg} /$ day) for methamphetamine dependence. Addiction. (2009) 104:224-33. doi: 10.1111/j.1360-0443.2008.02437.x

55. Anglin MD, Burke C, Perrochet B, Stamper E, Dawud-Noursi S. History of the methamphetamine problem. J Psychoact Drugs. (2000) 32:13741. doi: 10.1080/02791072.2000.10400221

56. Bray GA. Use and abuse of appetite-suppressant drugs in the treatment of obesity. Ann Intern Med. (1993) 119:70713. doi: 10.7326/0003-4819-119-7_Part_2-199310011-00016

57. He JC, Xie Y, Tao JY, Su H, Wu WX, Zou SZ, et al. Gender differences in socio-demographic and clinical characteristics of methamphetamine inpatients in a Chinese population. Drug Alcohol Depend. (2013) 130:94100. doi: 10.1016/j.drugalcdep.2012.10.014

58. Fenn JM, Laurent JS, Sigmon SC. Increases in body mass index following initiation of methadone treatment. J Subst Abuse Treat. (2015) 51:5963. doi: 10.1016/j.jsat.2014.10.007

59. Dolezal BA, Chudzynski J, Storer TW, Abrazado M, Penate J, Mooney L, et al. Eight weeks of exercise training improves fitness measures in methamphetamine-dependent individuals in residential treatment. J Addict Med. (2013) 7:122-8. doi: 10.1097/ADM.0b013e318282475e

60. Li JX, Hong Y, Chan KM. Tai Chi: physiological characteristics and beneficial effects on health. Br J Sports Med. (2001) 35:148-56. doi: 10.1136/bjsm.35.3.148

61. Siu PM, Yu AP, Benzie IF, Woo J. Effects of 1-year yoga on cardiovascular risk factors in middle-aged and older adults with metabolic syndrome: a randomized trial. Diabetol Metab Syndr. (2015) 7:12. doi: 10.1186/s13098-015-0034-3

62. Ladawan S, Klarod K, Philippe M, Menz V, Versen I, Gatterer H, et al. Effect of Qigong exercise on cognitive function, blood pressure and cardiorespiratory fitness in healthy middle-aged subjects. Complement Ther Med. (2017) 33:3945. doi: 10.1016/j.ctim.2017.05.005

63. Jing L, Jin Y, Zhang X, Wang F, Song Y, Xing F. The effect of Baduanjin qigong combined with CBT on physical fitness and psychological health of elderly housebound. Medicine (Baltimore). (2018) 97:e13654. doi: 10.1097/MD.0000000000013654

64. Zhang M, Xv G, Luo C, Meng D, Ji Y. Qigong Yi Jinjing promotes pulmonary function, physical activity, quality of life and emotion regulation self-efficacy in patients with chronic obstructive pulmonary disease: a pilot study. J Altern Complement Med. (2016) 22:810-7. doi: 10.1089/acm.2015.0224

65. Herrero JL, Khuvis S, Yeagle E, Cerf M, Mehta AD. Breathing above the brain stem: volitional control and attentional modulation in humans. $J$ Neurophysiol. (2018) 119:145-59. doi: 10.1152/jn.00551.2017
66. Zelano C, Jiang HD, Zhou GY, Arora N, Schuele S, Rosenow $\mathrm{J}$, et al. Nasal respiration entrains human limbic oscillations and modulates cognitive function. J Neurosci. (2016) 36:1244867. doi: 10.1523/JNEUROSCI.2586-16.2016

67. Homma I, Masaoka Y. Breathing and emotion. J Physiol Sci. (2013) 63:S109.

68. Yeh GY, Wang C, Wayne PM, Phillips R. Tai chi exercise for patients with cardiovascular conditions and risk factors: a systematic review. $J$ Cardiopulm Rehabil Prev. (2009) 29:152-60. doi: 10.1097/HCR.0b013e318 $1 \mathrm{a} 33379$

69. Zheng GH, Li SZ, Huang MM, Liu FW, Tao J, Chen LD. The effect of Tai Chi training on cardiorespiratory fitness in healthy adults: a systematic review and meta-analysis. PLoS ONE. (2015) 10:20. doi: 10.1371/journal.pone.0117360

70. Salmoirago-Blotcher E, Wayne PM, Dunsiger S, Krol J, Breault C, Bock $\mathrm{BC}$, et al. Tai Chi is a promising exercise option for patients with coronary heart disease declining cardiac rehabilitation. J Am Heart Assoc. (2017) 6:11. doi: 10.1161/JAHA.117.006603

71. Carpio-Rivera E, Moncada-Jimenez J, Salazar-Rojas W, Solera-Herrera A. Acute effects of exercise on blood pressure: a meta-analytic investigation. Arq Bras Cardiol. (2016) 106:422-33. doi: 10.5935/abc.20160064

72. Hartley L, Lee MS, Kwong JS, Flowers N, Todkill D, Ernst E, et al. Qigong for the primary prevention of cardiovascular disease. Cochrane Database Syst Rev. (2015). CD010390. doi: 10.1002/14651858.CD010390.pub2

73. Lee MS, Lee MS, Choi ES, Chung HT. Effects of Qigong on blood pressure, blood pressure determinants and ventilatory function in middleaged patients with essential hypertension. Am J Chin Med. (2003) 31:48997. doi: 10.1142/S0192415X03001120

74. Yeh GY, Wang C, Wayne PM, Phillips RS. The effect of Tai Chi exercise on blood pressure: a systematic review. Prev Cardiol. (2008) 11:829. doi: 10.1111/j.1751-7141.2008.07565.x

75. Lee MS, Lee MS, Kim HJ, Moon SR. Qigong reduced blood pressure and catecholamine levels of patients with essential hypertension. Int J Neurosci. (2003) 113:1691-701. doi: 10.1080/00207450390245306

76. Lin CY, Wei TT, Wang CC, Chen WC, Wang YM, Tsai SY. Acute physiological and psychological effects of Qigong exercise in older practitioners. Evid Based Complement Alternat Med. (2018) 2018:4960978. doi: 10.1155/2018/4960978

Conflict of Interest: The authors declare that the research was conducted in the absence of any commercial or financial relationships that could be construed as a potential conflict of interest.

Copyright (c) $2020 \mathrm{Zhu}$, Jiang, Xu and Schöllhorn. This is an open-access article distributed under the terms of the Creative Commons Attribution License (CC BY). The use, distribution or reproduction in other forums is permitted, provided the original author(s) and the copyright owner(s) are credited and that the original publication in this journal is cited, in accordance with accepted academic practice. No use, distribution or reproduction is permitted which does not comply with these terms. 